\title{
Comparative growth and development of autumn and spring spawned Atlantic herring larvae reared in large enclosed ecosystems
}

\author{
J. C. Gamble, P. MacLachlan \& D. D. Seaton \\ Department of Agriculture and Fisheries for Scotland, Marine Laboratory, P.O. Box 101, Victoria Road, Aberdeen, Scotland, \\ United Kingdom
}

\begin{abstract}
Populations of Atlantic herring larvae Clupea harengus harengus L. were reared in $300 \mathrm{~m}^{3}$ in situ plastic enclosures for about $60 \mathrm{~d}$ in Sep to Nov 1978 and for about $90 \mathrm{~d}$ in Apr to Jul 1980. The addition of soluble organic effluent from North Sea oil production had little direct effect on the larvae in 1980 and, in 1978 , it was difficult to discern effects due to the inadvertent trapping of juvenile fish predators. Developmental progression of the enclosed populations of larvae, as defined by morphological staging, differed between seasons. While developmental rate was undoubtedly correlated with growth rate, initial size of larvae $(0.067 \mathrm{mg}$ in autumn 1978 and $0.138 \mathrm{mg}$ in spring 1980) had a significant effect on early development. It is suggested that the small egg size of the Minch autumn spawned herring serves to delay the developmental rate of the larva at a time when temperature and food conditions could stimulate rapid growth. This mechanism helps to ensure that larvae which hatch in September do not metamorphose before the onset of winter. In contrast the large egg and hatching larva of the Clyde spring spawner favours rapid progression through the developmental stages to early metamorphosis.
\end{abstract}

\section{INTRODUCTION}

The Atlantic herring Clupea harengus harengus L. is unusual among clupeoids because it is a synchronous spawner producing a single batch of eggs (Blaxter \& Hunter 1982). However, the different stocks of herring in both east and west Atlantic spawn at different times during the year and the egg sizes, like those of many other fish species (Bagenal 1971), vary according to season (Blaxter \& Hempel 1963). The dry weight of herring eggs laid around the coasts of the British Isles varies over a 2:1 range (Hempel \& Blaxter 1967) with the largest eggs being spawned in December to March and the smallest in July to September.

Recently Sinclair \& Tremblay (1984) emphasized that, while the spawning of the various populations or stocks of herring in the North Atlantic can occur throughout the year, the metamorphosis from larval to juvenile eggs is restricted to a period from April to October. In consequence the lengths of the developmental periods of the larvae are dependent on spawning time. Larvae from the large winter-spring spawned eggs metamorphose within 3 to 6 mo while those from the smaller summer-winter eggs overwinter as larvae to metamorphose 7 to 8 mo later. The Minch autumn spawners (De Silva 1973) and the Clyde spring spawners (Marshall et al. 1937) used in our experiments fit into this pattern.

The significance of the seasonal egg size differences in herring stocks has been a source of speculation for many years. Since, in relation to body weight, the variation in egg sizes is considerably more than that of the respective gonads, the most obvious direct effect is on the fecundity of the various stocks (Bagenal 1966, Hempel \& Blaxter 1967, Burd \& Howlett 1974). Consequently explanations have tended to centre on the particular ecological advantages of producing fewer but larger eggs in the winter-spring period as opposed to more abundant small eggs spawned in the late summer-autumn (Blaxter \& Hempel 1963, Hempel 1965, Mann \& Mills 1979). Broadly it is felt that the large eggs produce larvae which are able to survive longer in the poorer feeding conditions of the spring season while the greater fecundity in the autumn serves to counteract the greater predation pressure on the larvae at that time. Ware (1975) considered egg 
size of pelagic fish eggs in terms of susceptibility to predation and concluded that there is an advantage in producing small eggs when the incubation period is short. Since incubation time is directly related to temperature (Blaxter 1956) egg size should be minimal in summer.

The timing of spawning in herring populations and other fish has also been the source of much speculation (e.g. Iles 1964, Cushing 1967, 1969, 1973, 1975, Iles \& Sinclair 1982, Sinclair \& Tremblay 1984). Initially the timing was linked to primary production cycles (Iles 1964, Cushing 1967) but, because the time of spawning tended to be less variable than the timing of primary production blooms, Cushing (1975) postulated that larval survival and the subsequent extent of recruitment might depend on the closeness of the match between the 2 events.

This attractive 'match-mismatch' theory of Cushing has recently been challenged by Sinclair \& Tremblay (1984) who, developing the larval retention area hypothesis of Iles \& Sinclair (1982), have suggested that timing of spawning of herring is determined by 2 other constraints. These are firstly that the herring larvae of a particular population develop within a discrete retention area at a rate attuned to the particular oceanographic situation of that area, and secondly that metamorphosis only takes place within a specific period of the year. The timing of spawning and the size of the eggs are thus geared to achieve metamorphosis at the appropriate time under certain specific and reasonably predictable environmental circumstances.

This paper presents data on the growth and morphological developments of spring and autumn spawned herring larvae reared on natural zooplankton in large in situ enclosures. The larvae came from 2 different stocks although both spawned on the west coast of Scotland. Spring spawners were taken from the Clyde while autumn spawners came from the Minch. The egg sizes were predictably different (Hempel \& Blaxter 1967) yet larvae from both stocks metamorphosed within the period April to July (Sinclair \& Tremblay 1984).

The initial objectives of the work were concerned with evaluating the effects of soluble organic contaminants ('produced water') from North Sea oil operations. However, since uncontaminated enclosures, referred to as controls, were deployed in each season and, since the direct effects of the pollutant on the larvae were seen to be minimal, the 2 experiments provided an ideal opportunity to compare larval herring reared during different seasons.

Large enclosures have several advantages over smaller rearing systems. When deployed in the sea they are subject to ambient seasonal light and temperature regimes. Light levels are slightly reduced (to about $80 \%$ ) and there is much less vertical mixing (Steele et al. 1977). However, the captive water columns become stratified in parallel with the surrounding sea. Several species of fish larvae have been shown to survive well in large systems (Øiestad 1982) and have grown at rates equivalent to those measured in natural populations (Gamble et al. 1981). It has also become apparent that in these systems larvae can initiate feeding and survive at considerably lower food concentrations than predicted from tank experiments (Houde 1978, Hunter 1981).

In this paper we hope to show that the patterns of growth and development of autumn and spring spawned herring larvae relate to their respective growth and metamorphosis strategies. In showing such we offer an alternative or additional explanation for seasonal egg size variation.

\section{MATERIALS AND METHODS}

System design and procedures. The enclosures (bags) used in these experiments were of the large open cylinder type (Davies et al. 1980, Gamble et al. 1981). Four were deployed in each experiment. Each bag was a $4.7 \mathrm{~m}$ diameter translucent, nylon-reinforced PVC (Plastolene 946) cylinder, which tapered below $16 \mathrm{~m}$ depth to terminate in a $0.5 \mathrm{~m}$ diameter polythene funnel at $19.5 \mathrm{~m}$. The estimated volume was just over $300 \mathrm{~m}^{3}$. The sedimented contents within the funnel were pumped through a $2.5 \mathrm{~cm}$ diameter hose leading outside the bag to the system service raft. Each bag was supported by an octagonal collar of high density polystyrene blocks held within a steel boxsection framework.

Plasticizers which would significantly add to the dissolved organic matter in the enclosed water columns (Davies et al. 1980) were leached out of the PVC material by soaking the partially filled bags in situ for 1 wk before addition of the eggs. The water used for leaching was released by collapsing each bag onto a horizontal mesh frame suspended beneath the bottom cone. The bags were refilled by lifting with the mouth held open from the frame depth of $22 \mathrm{~m}$ to the surface. This procedure enclosed approximately $95 \%$ of the total volume of water required to fill the bag $\left(300 \mathrm{~m}^{3}\right)$. The final filling was completed with a large volume piston pump.

At the end of both 1978 and 1980 experiments the contents of each bag were evacuated with large volume piston pumps through a $68 \mu \mathrm{m}$ mesh net. When each bag was virtually empty (about $20 \mathrm{~m}^{3}$ of water remaining), a $0.5 \mathrm{~m}$ diameter $68 \mu \mathrm{m}$ plankton net was attached to the base of the bag in place of the polythene funnel. The bag was then lifted out of the 
water, mouth first, thus draining the final contents through the $68 \mu \mathrm{m}$ net.

Larval incubation and stocking. Ripe gonads were taken from adult herring spawning in August/September 1978 in the Minch, Scotland $\left(57^{\circ} 49^{\prime} \mathrm{N}\right.$, $05^{\circ} 50^{\prime} \mathrm{W}$ ) and in March 1980 in the Clyde Sea, Scotland $\left(55^{\circ} 23^{\prime} \mathrm{N}, 05^{\circ} 12^{\prime} \mathrm{W}\right)$. The gonads were stored on ice and immediately transported to the laboratory where, following the procedure outlined in Gamble et al. (1981), eggs were spread as a monolayer on glass plates and fertilized in vitro. In 1978 eggs from 9 females fertilized by a sperm mixture from 4 males were incubated at $9^{\circ} \mathrm{C}$ on $30 \times 200 \mathrm{~mm}$ ground glass plates. In 1980, 8 females and 5 males provided fertilized eggs which were reared on $150 \times 200 \mathrm{~mm}$ glass plates. Care was taken to ensure that eggs from each female were distributed equally among the 4 bags. Fertilization took place on 1 September 1978 and during the night of 31 March to 1 April 1980. In 1978 the plated eggs were transferred to the bags $2 \mathrm{~d}$ after the onset of embryonic eye pigmentation at an ambient temperature of $11.9^{\circ} \mathrm{C}$. In 1980 , the developing eggs were placed in the bags at gastrulation much earlier in the incubation. Ambient seawater temperature was $7.8^{\circ} \mathrm{C}$.

Larval sampling and analysis. The number of larvae hatched from the glass plates into the bags in 1978 and 1980 was determined by comparing photographs of the plates of eggs before and after hatching. Larvae were collected routinely at $4 \mathrm{~d}$ intervals using a $1 \mathrm{~m}$ diameter $350 \mu \mathrm{m}$ standard net towed vertically up the central axis of the bag at $0.8 \mathrm{~m} \mathrm{~s}^{-1}$. Net propulsion was provided by a counterweight-pulley system. All collections were made at dusk although for about $4 \mathrm{wk}$ around the summer solstice the ambient light remained above 'dusk' levels. During this period routine metre-net collections were made at 0000 h GMT (midnight). Dead larvae were removed with the sedimented material from the bottom cone of the bag initially on a daily basis but at less frequent intervals later in the experiment.
All larval samples, except for some set aside for lipid analysis (Gatten et al. 1983), were immediately preserved in $2 \%$ formalin, made up in isotonic, $15 \%$, sea water solution (Blaxter 1971) and a maximum of 20 fixed individuals were taken for morphometric analysis. In this subsample the largest and the smallest larvae were selected and the remainder picked at random. Total and standard lengths (tip of snout to end of notocord in preflex or to end of hypural plate in postflex larvae) were measured within 24 h of capture. Morphological staging was determined by the scheme of Doyle (1977). The larvae were then freeze-dried for at least $24 \mathrm{~h}$ before dry-weighing.

North Sea oil 'produced water' was added to 2 of the 4 bags in autumn 1978 and in spring 1980. Additions took place immediately after removal of the incubation plates on 19 September 1978 and 23 April 1980. Further additions were made on 10 October 1978 and 5 May 1980. The concentration of 'oil by fluorescence' after the first additions in 1978 was 30 to $35 \mu \mathrm{g} \mathrm{l}^{-1}$ compared with 7 to $8 \mu \mathrm{g} \mathrm{l}^{-1}$ in 1980 .

Zooplankton. Routine samples of enclosed zooplankton were taken at approximately $4 \mathrm{~d}$ intervals with $68 \mu \mathrm{m}$ mesh nets fitted to a $40 \mathrm{~cm}$ bongo frame. The bongo was hauled up the central core of the bag during the day using the counterweight system. Filtration efficiency over the short haul distance in the bag was $79.6 \%$ in 1978 and $60.8 \%$ in 1980 . These differences were due to changes in net design and mesh porosity.

In spring 1980 the initial abundance of copepod nauplii was believed to be too low for larval survival at first feeding. The enclosed zooplankton populations were therefore enhanced by netted material added over a 2 wk period prior to larval hatching.

Fish larval feeding. Up to 20 larvae from each bag at each sampling were set aside for gut content examination. The guts were teased apart in glycerol, and gentian violet added to assist recognition of food items.

Nomenclature. To aid identification of the bag larval populations the following lettering system has been adopted: $\mathrm{T}=$ treated enclosure, i.e. produced-water

Table 1. Clupea harengus. Numbers of herring larvae introduced and subsequently removed from bags. T1, T2: bags treated with 'produced water'; $\mathrm{C} 1, \mathrm{C} 2$ : untreated control bags

\begin{tabular}{|c|c|c|c|c|c|c|c|c|}
\hline & $\mathrm{T} 1-78$ & $\mathrm{~T} 2-78$ & $\mathrm{C} 1-78$ & $\mathrm{C} 2-78$ & $\begin{array}{l}\text { Bag } \\
\qquad 1-80\end{array}$ & $\mathrm{~T} 2-80$ & $\mathrm{C} 1-80$ & $C 2-80$ \\
\hline Gonad collection & \multicolumn{4}{|c|}{31 Aug 1978} & \multicolumn{4}{|c|}{$30 \operatorname{Mar} 1980$} \\
\hline Incubation period (d) & \multirow{2}{*}{\multicolumn{4}{|c|}{$\begin{array}{r}14 \\
3\end{array}$}} & \multicolumn{4}{|c|}{20} \\
\hline Hatching period (d) & & & & & \multicolumn{4}{|c|}{6} \\
\hline Eggs introduced & 70840 & 76332 & 75146 & 82609 & 36835 & 30761 & 31971 & 30189 \\
\hline Eggs hatched & 50807 & 53494 & 59241 & 59614 & 23675 & 17396 & 18820 & 16989 \\
\hline$\%$ hatching success & 71.7 & 70.0 & 78.8 & 72.1 & 64.2 & 56.5 & 58.8 & 56.2 \\
\hline Larvae at emptying (live) & 0 & 3 & 1372 & 1470 & 30 & 32 & 165 & 136 \\
\hline Experimental duration (d) & 60 & 63 & 61 & 62 & 89 & 87 & 88 & 86 \\
\hline
\end{tabular}


added, $\mathrm{C}=$ control bag without pollutant. The pairmembers will be known as 1 and 2 and the year added as a suffix, e.g. T1-78 and C2-80.

\section{RESULTS}

\section{Incubation and hatching}

The incubation period for the 1980 spring-spawned eggs was considerably longer than for the autumnreared material (Table 1), due presumably to differences in ambient sea temperature $\left(7.5^{\circ} \mathrm{C}\right.$ in spring and $9^{\circ} \mathrm{C}$ increasing to $11.9^{\circ} \mathrm{C}$ in autumn) and possibly to the larger size of the spring herring eggs (Blaxter 1956). The hatching periods were noticeably affected since 70 to $80 \%$ of the autumn eggs had hatched within $3 \mathrm{~d}$ compared with only 55 to $65 \%$ by $6 \mathrm{~d}$ during spring. In both cases hatching in the bags was effectively terminated by removal of the racks of eggs. The dates of peak hatching, estimated to be 15 September 1978 and 20 April 1980, were taken as Day 0 in larval population ageing.
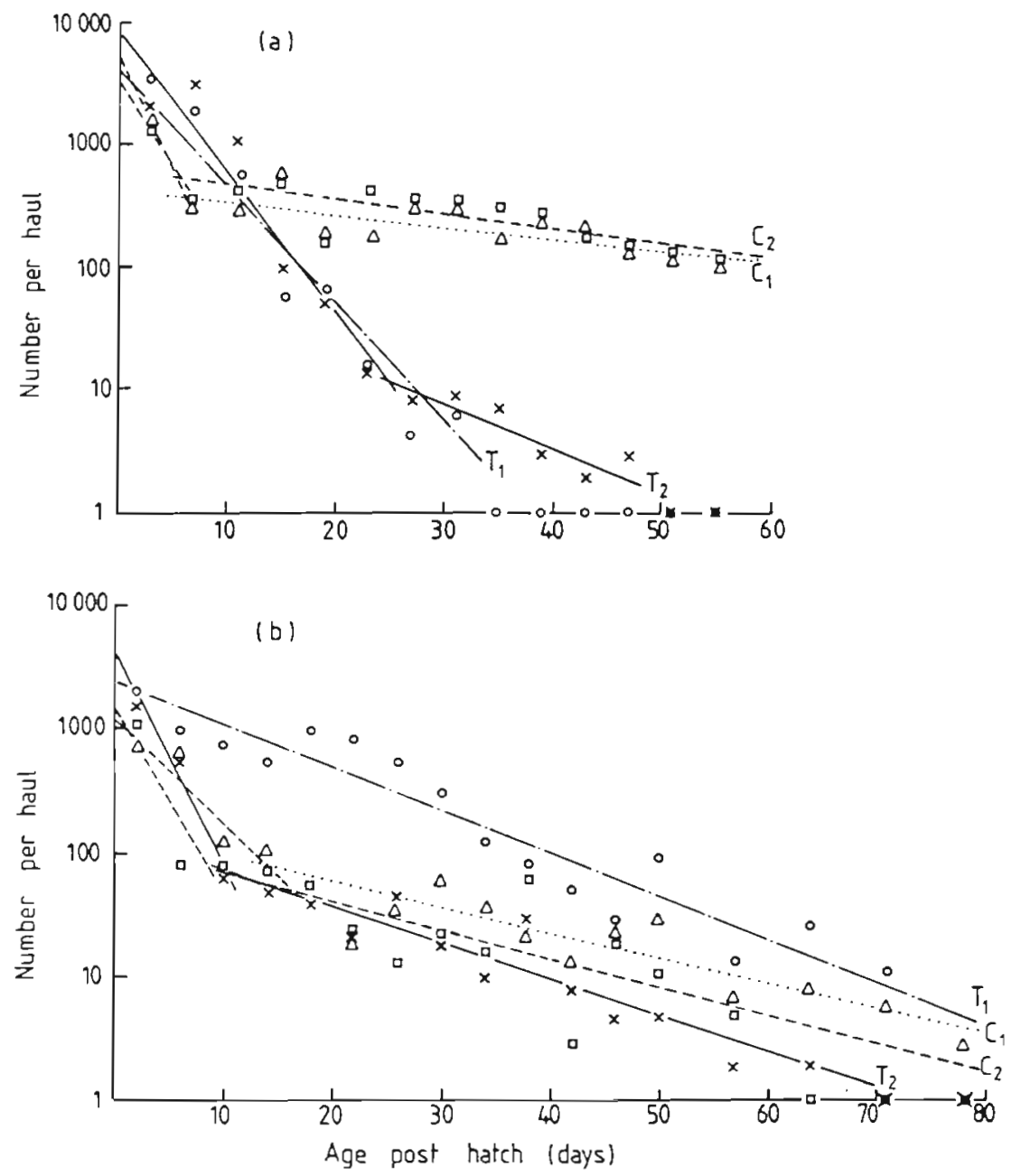

Fig. 1. Clupea harengus. Mortality profiles of the enclosed populations of herring larvae expressed as numbers per metre-net haul, (a) autumn 1978, (b) spring 1980 . Exponential regression lines drawn relate to data presented in Table 2, 10 to $57 \mathrm{~d}$ period used for $\mathrm{C}^{-}$-, C2- and T2-80. $\mathrm{T}$ : treated populations: $\mathrm{C}$ : control populations. $(\Delta) \mathrm{C} 1$; $(D) \mathrm{C} 2$; (O) T1; (X) T2
The newly hatched yolk-sac larvae were almost twice as heavy in the spring than in the autumn (0.067 $\mathrm{mg}$ dry wt in autumn 1978 compared with $0.138 \mathrm{mg}$ in spring 1980 ). Thus, though twice as many eggs were added to the autumn 1978 bags compared with spring 1980 (Table 1), the total biomass of hatched larvae was only $1.4 \times$ greater in 1978 .

\section{Mortality}

As in 1977 (Gamble at al. 1981), most of the larval populations showed an initial, pre-feeding rapid decline in numbers followed by a period of lower mortality for the remainder of the experiment (Fig. 1) single exponential regression line gave an estimate of mortality rate in those bags where the larval population declined regularly throughout, but where the mortality pattern changes, 2 exponential regressions were itted (Table 2).

There was no significant difference between the exponential regression slopes and intercepts for the 7 
Table 2. Clupea harengus. Instantaneous daily mortality rates of herring larvae derived from metre-net hauls over specified periods (days post hatch)

\begin{tabular}{|rcccccccccc|}
\hline \multirow{2}{*}{ Period } & \multicolumn{4}{c}{ Bag } & \multicolumn{2}{c}{ Period } & \multicolumn{2}{c}{ Bag } \\
& T1-78 & T2-78 & C1-78 & C2-78 & & T1-80 & T2-80 & C1-80 & C2-80 \\
\hline $3-7$ & - & - & 0.44 & 0.34 & $2-10$ & - & 0.395 & 0.203 & 0.325 \\
$3-27$ & - & 0.267 & - & - & $2-57$ & 0.081 & - & - & - \\
$3-43$ & 0.221 & - & - & - & $2-78$ & 0.085 & - & - & 0.046 & 0.052 \\
$7-55$ & - & - & 0.022 & 0.028 & $10-57$ & - & 0.067 & 0.01 & 0.067 \\
$27-55$ & - & 0.083 & - & - & $10-78$ & - & 0.067 & 0.067 \\
\hline
\end{tabular}

to $55 \mathrm{~d}$ mortality periods of the $\mathrm{C} 1-78$ and $\mathrm{C} 2-78$. Furthermore both bags contained similar number of larvae at emptying (Table 1) which, when related to calculated numbers per haul at the end of the experiment estimated from the regression lines, were 111 in C1-78 and 117 in C2-78. Comparison with the actual numbers present (Table 1) indicated that each metrenet haul removed about $8 \%$ of the larval population. Thus, taking account of differences in experimental duration (Table 1) and in the number of net hauls, instantaneous daily rates of mortality induced by metre-net collection ranged from 0.0178 to 0.0184 in autumn 1978 and 0.0153 to 0.0156 in spring 1980 .

Similar absolute and estimated terminal population comparisons in spring 1980 indicated much lower catching efficiency at the time of emptying. However, the larvae in 1980 were much larger (many had metamorphosed) at the end of this considerably longer experiment and it was clear from direct observation that, as they grew and formed schools, the larvae became more adept at avoiding the net. Hence net data obtained for 1980 larvae older than those of the 1978 experiment could have underestimated larval numbers.

The high rates of larval mortality in T1- and T2-78 were correlated with the addition of 'produced water' (Fig. 1) but on emptying, juvenile fish were also found within these particular bags. These individual fish - a $26.5 \mathrm{~cm}$ Pollachius virens in T1-78 and an $8 \mathrm{~cm} \mathrm{Mer-}$ langius merlangus and $11.5 \mathrm{~cm}$ Sprattus sprattus in T278 - can feed on herring larvae (J. Hislop pers. comm.) and would be easily capable of removing the total larval biomass produced within the periods specified, 1.00 and $1.13 \mathrm{~g}$ dry weight in T1-78 and T2-78 respectively. They must have been trapped in the bags during filling.

No obvious effects on mortality were in evidence in spring 1980 since the treated populations behaved very differently (Fig. 1). One (T2-80), together with C1and C2-80, declined rapidly initially, while T1-80 decreased steadily throughout the experiment. A consequence of this difference in mortality pattern was that during initial feeding stages the larval population in T1-80 was more than $10 \times$ larger than the other 3 populations.

\section{Growth rates}

\section{Length}

The data (Fig. 2) were described by a linear relation rather than a more complex growth model of the von Bertalanffy or Gompertz type (Ricker 1979). Between sampling intervals growth rates were not necessarily constant, with the consequence that oscillating patterns were apparent which in some cases varied consistently in different enclosed larval populations. For instance, in C1- and C2-78 larval lengths increased

Table 3. Clupea harengus. Growth of herring larvae in bags. Regression parameters of linear increase in standard length (mm) with age (days post hatch). Relation: standard length $=a+b$ (age)

\begin{tabular}{|lcccccc|}
\hline Bag & $\mathrm{a}$ & $\mathrm{SE}$ & $\mathrm{b}$ & $\mathrm{SE}$ & $\mathrm{r}$ & $\mathrm{n}$ \\
\hline $\mathrm{T} 1-78$ & 7.030 & 0.185 & 0.152 & 0.010 & 0.784 & 133 \\
$\mathrm{~T} 2-78$ & 6.467 & 0.161 & 0.201 & 0.007 & 0.912 & 160 \\
$\mathrm{C} 1-78$ & 7.038 & 0.280 & 0.137 & 0.008 & 0.711 & 300 \\
C2-78 & 6.899 & 0.290 & 0.145 & 0.008 & 0.721 & 299 \\
T1-80 & 8.689 & 0.303 & 0.156 & 0.008 & 0.751 & 294 \\
T2-80 & 5.351 & 0.355 & 0.337 & 0.011 & 0.913 & 203 \\
C1-80 & 5.386 & 0.423 & 0.309 & 0.011 & 0.875 & 250 \\
C2-80 & 3.280 & 0.418 & 0.407 & 0.011 & 0.931 & 208 \\
\hline
\end{tabular}



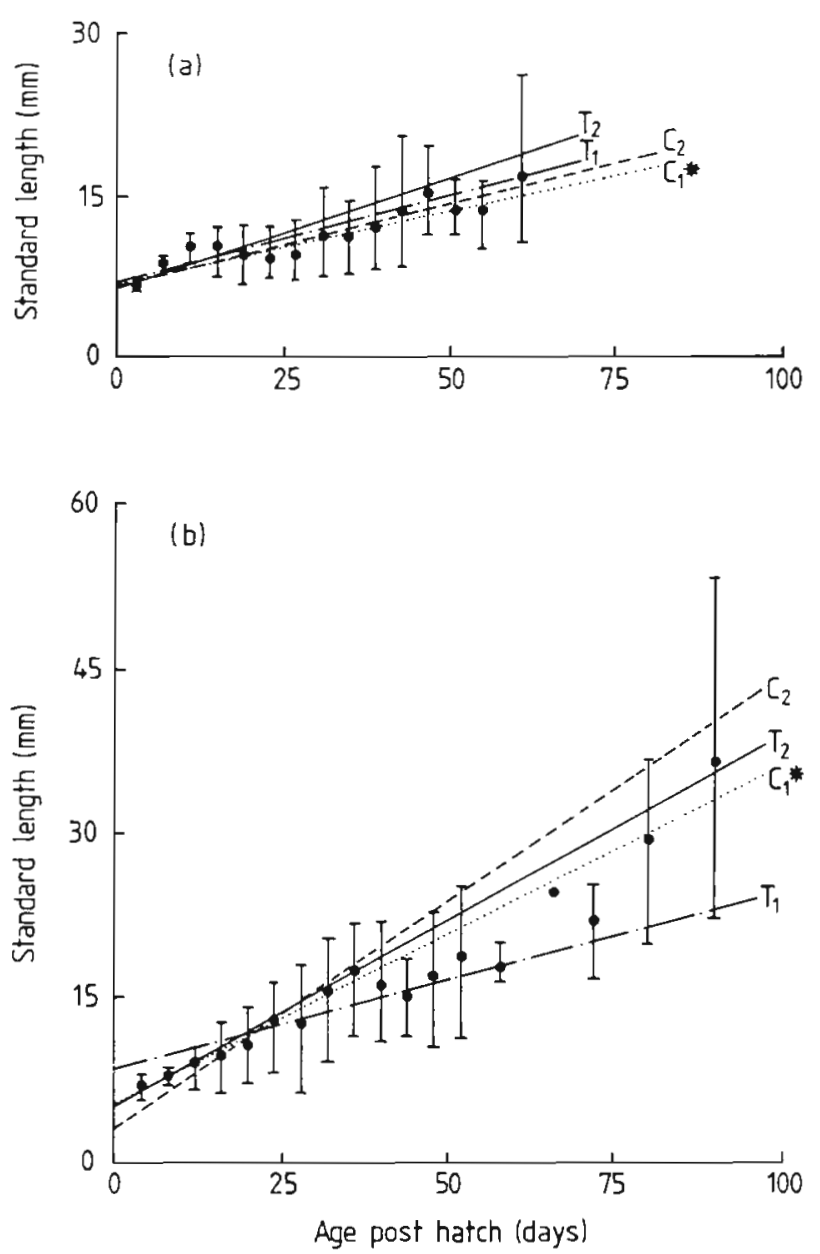

Fig. 2. Clupea harengus. Growth of herring larvae in bags; increase of standard length in (a) autumn 1978, means and range bars for control C1-78, (b) spring 1980, means and range bars for control C1-80. Linear regression lines shown for other bag populations: $T$, treated populations; $C$, control populations. ' line relating to detailed data

rapidly over the first 3 sampling dates, decreased for the next 2, then increased again (Fig. 2a). If any complex model were fitted to this data it might best be a polynomial tailored to the oscillations of the observed progressions.

The regression parameters of the linear relation between standard length and age are shown in Table 3; all were significant, $\mathrm{P}<<0.001$. The slopes of these regressions ranged from $0.137 \mathrm{~mm} \mathrm{~d}^{-1}$ to $0.407 \mathrm{~mm} \mathrm{~d}^{-1}$ with the greatest range and highest ranges occurring in spring 1980. Comparison of the various slopes indicated that the slope of the C2-78 population growth curve was significantly different $(P<0.001)$ from the other enclosed populations in that year. Tests between the other bags in autumn 1978 revealed no significant differences. In spring 1980 the rates were more variable than in autumn 1978. They were significantly different from the spring 1978 val- ues and from each other except for C1-80 and T2-80. It was also noticeable that growth in T1-80 was considerably less than that of other enclosed populations of that year, its rate of $0.156 \mathrm{~mm} \mathrm{~d}^{-1}$ being comparable with the fastest rates of the autumn spawned larvae in 1978.

\section{Weight}

Dry weight increased exponentially with larval age (Fig. 3). However, again the growth progressions, as with the standard length relations, appeared oscillatory than steadily incremental.

It was noticeable in spring 1980 that there was a reduction in weight of larvae during the first week
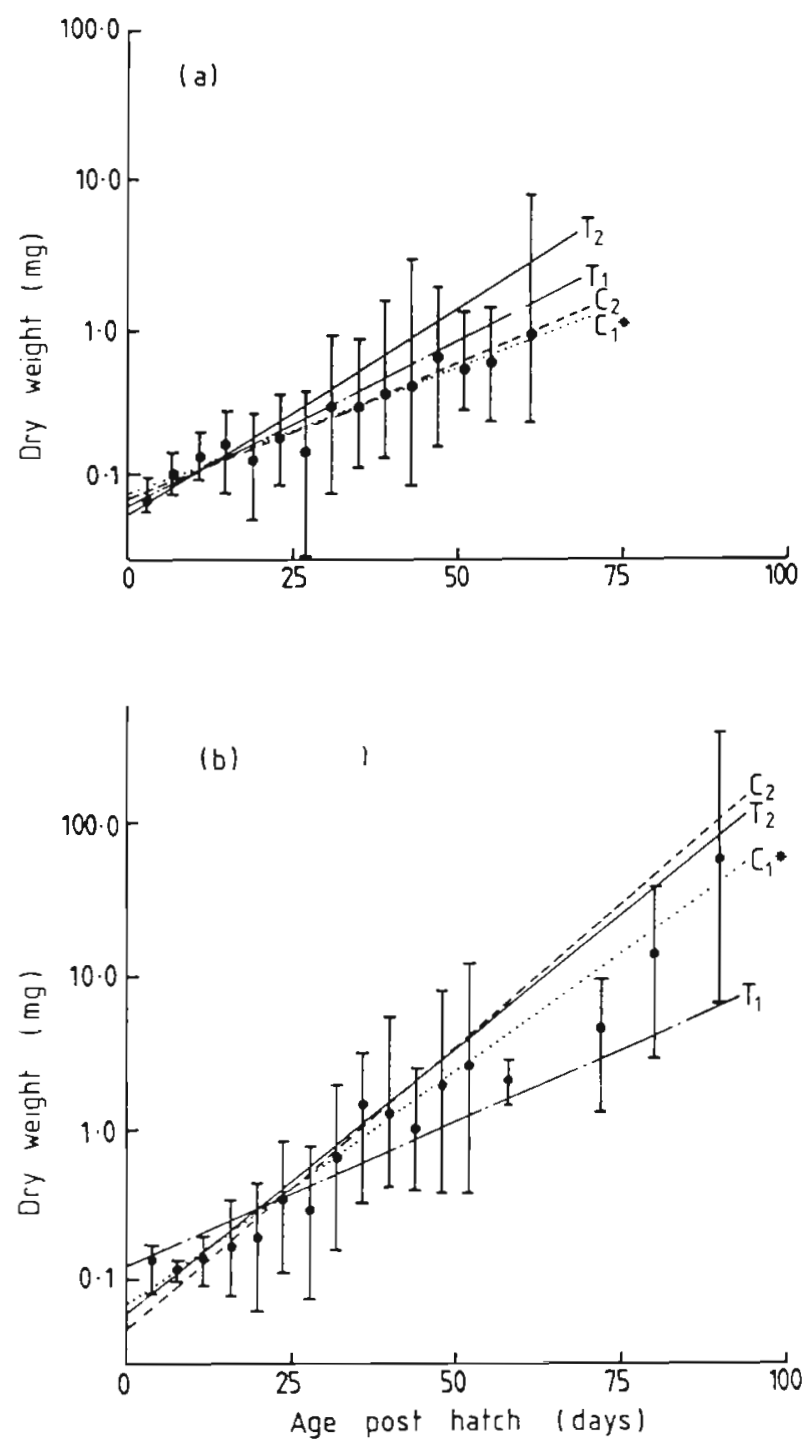

Fig. 3. Clupea harengus. Growth of herring larvae in bags, increase of dry weight in (a) autumn 1978, (b) spring 1980. Same data illustrated as in Fig. $3^{*}$ line relating to detailed data 
after hatching. This weight loss, which averaged $21 \%$ reduction in body weight between Days 3 and 7 posthatching in spring 1980, was not evident in our data in autumn 1978. However, the smaller body size of the autumnal larvae and higher ambient temperature at hatching, $11.9^{\circ} \mathrm{C}$ in autumn compared to $7.8^{\circ} \mathrm{C}$ in spring, would both have contributed to a more rapid consumption of yolk in the autumn and accelerated the initiation of exogenous feeding. Hence the shorter period of weight loss in the autumn could have been missed in our $4 \mathrm{~d}$ sampling interval.

Comparisons of growth rates based on dry weights within and between years led to similar conclusions to those made from standard length comparisons. The highest daily instantaneous growth coefficient $(\mathrm{g})$ and the greatest variability was again in spring 1980 when coefficients ranged from 0.045 to 0.082 (Table 4), equivalent to daily specific growth rates of 4.6 to $8.6 \%$ (Table 5). The growth rate in T1-80 was again considerably less than in all other bags in 1980 . The growth rates in C2-80 and T2-80 were not significantly differ- ent. In autumn 1978 there was no significant difference between the 2 lowest growth rates measured in C1and C2-78.

\section{Size range}

Distinct size ranges, as often observed in tank rearing experiments (Blaxter 1975), developed in many of the enclosed populations. The weight ranges of larvae in $1 \mathrm{bag}, \mathrm{C} 1-80$, at emptying, spread over 2 orders of magnitude, although a range of 1 order of magnitude was most frequently observed. Since the largest and smallest larvae were selected from each sample, maximum and minimum growth rates of the population could be estimated from regression analysis of these sets of points (Table 5). A sample size of 10 was set as a minimum in such analyses. However, the most meaningful estimates of growth rate were probably to be made from the populations of larvae collected at emptying. Such 'ultimate' maximum and minimum growth

Table 4. Clupea harengus. Growth of herring larvae in bags. Regression parameters of exponential increase in dry weight (mg) with age (days post hatch). Relation: $\mathrm{Wt}=\mathrm{Wo}_{\mathrm{O}} \exp \mathrm{gt}$; linearised to $\ln \mathrm{Wt}=\ln \mathrm{Wo}_{\mathrm{o}}+\mathrm{gt}$, where Wo $=$ weight at time zero; Wt $=$ weight at time $t(d) ; g=$ instantaneous coefficient of growth

\begin{tabular}{|lllllll|}
\hline Bag & lnWo & SE & g & SE & r & n \\
\hline T1-78 & -2.766 & 0.053 & 0.052 & 0.003 & 0.835 & 133 \\
T2-78 & -2.897 & 0.042 & 0.064 & 0.002 & 0.935 & 160 \\
C1-78 & -2.611 & 0.071 & 0.040 & 0.002 & 0.759 & 300 \\
C2-78 & -2.680 & 0.074 & 0.044 & 0.002 & 0.780 & 299 \\
T1-80 & -2.107 & 0.070 & 0.045 & 0.002 & 0.819 & 294 \\
T2-80 & -2.765 & 0.081 & 0.082 & 0.002 & 0.923 & 203 \\
C1-80 & -2.647 & 0.078 & 0.072 & 0.002 & 0.916 & 250 \\
C2-80 & -3.007 & 0.076 & 0.087 & 0.002 & 0.949 & 208 \\
\hline
\end{tabular}

Table 5. Clupea harengus. Daily specific growth rates (SGR) of herring larvae calculated from exponential regression coefficient (") and from direct comparison of sizes at the beginning and the end of the experiment ( $" \cdot)$. SGR expressed as $\%$ dry weight $d^{-1}$

\begin{tabular}{|c|c|c|c|c|c|c|c|c|}
\hline \multirow{3}{*}{$\begin{array}{l}\text { Bag } \\
\text { Population }\end{array}$} & \multicolumn{4}{|c|}{1978 (Autumn) } & \multicolumn{4}{|c|}{1980 (Spring) } \\
\hline & T1-78 & $\mathrm{T} 2 \cdot 78$ & C1-78 & $\mathrm{C} 2-78$ & T1-80 & $\mathrm{T} 2-80$ & $\mathrm{C} 1-80$ & C2-80 \\
\hline & & & & & & & & \\
\hline regression $\left({ }^{\circ}\right)$ & 5.34 & 6.61 & 4.08 & 4.50 & 4.60 & 8.55 & 7.47 & 9.09 \\
\hline \multicolumn{8}{|l|}{ Max. weight } & 10.43 \\
\hline $\begin{array}{l}\text { Min. weight } \\
\text { regression (") } \\
\text { Ultimate }\end{array}$ & 5.13 & 5.65 & 2.53 & 2.53 & 3.45 & 7.12 & 5.31 & 8.16 \\
\hline \multicolumn{9}{|l|}{ Ultimate } \\
\hline minimum ( $\cdots)$ & - & - & 2.14 & 1.48 & 2.37 & 5.40 & 4.47 & 6.50 \\
\hline \multicolumn{9}{|c|}{$\begin{aligned} \therefore \mathrm{SGR} & =100(\exp \mathrm{g}-1) \\
\therefore \mathrm{SGR} & =[(\ln W 2-\ln W 1) /(\mathrm{t} 2-\mathrm{t} 1\end{aligned}$} \\
\hline
\end{tabular}


rates (Table 5) for dry weight exceeded $9 \%$ daily specific growth rate (SGR) in C1-and C2-80 while the smallest surviving larva in C2-78 achieved only a $1.5 \% \mathrm{~d}^{-1} \mathrm{SGR}$. These SGR values were equivalent to standard length growth rates of 0.54 to 0.57 and $0.06 \mathrm{~mm} \mathrm{~d}^{-1}$ respectively.

Comparison of the maximum and minimum instantaneous growth rates of the enclosed populations, obtained from exponential regressions, indicated that there were greater contrasts between the minima than between the maxima. However, in autumn 1978 there was no difference between the maximum or minimum rates while, in spring 1980 , only T1-80 departed significantly at both extremes from the other populations of that year (Table 5).

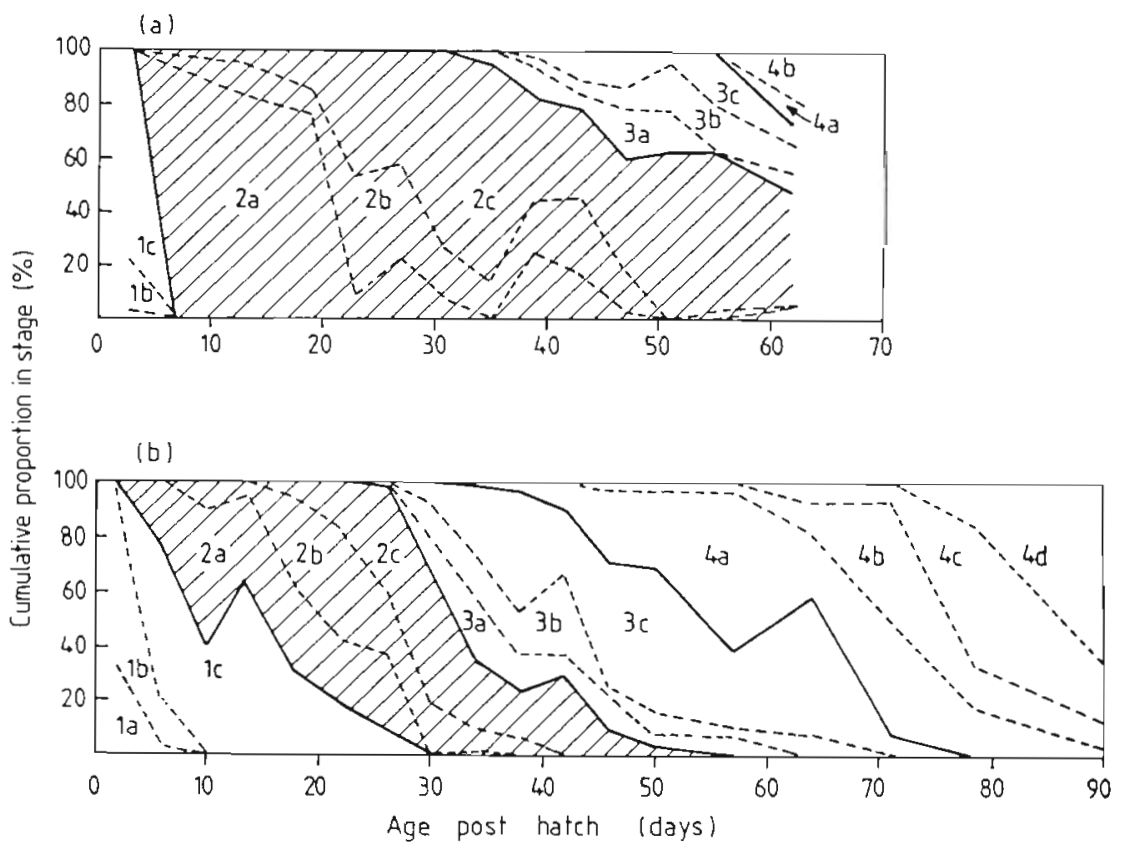

\section{Morphological stage}

Fig, 4 represents the progression through the developmental stages, as defined by Doyle (1977), for the combined samples of larvae from the autumn 1978 and from the spring 1980 experiments. Metamorphosis is defined as occurring at Stage $4 c$, but the main features which characterised each stage were: Stage 1. disappearance of yolk sac; Stage 2, differentiation of dorsal fin; Stage 3, dorsal upturn of posterior tip of notochord; Stage 4, relative shortening of gut. It is clear from Fig. 4 and from the mean ages at each stage (Table 6) that the rate and pattern of morphological development differed between autumn and spring spawned larvae.

Table 6. Clupea harengus. Mean ages at morphological stage for combined herring larval samples from each year. Age in days after hatching; n: sample size; <: overestimate of individuals in stage at onset of sampling; >; underestimate of individuals in stage at termination (Fig, 5)

\begin{tabular}{|c|c|c|c|c|}
\hline \multirow[t]{2}{*}{ Stage } & \multicolumn{2}{|c|}{1978 (Autumn) } & \multicolumn{2}{|c|}{1980 (Spring) } \\
\hline & Age & $\mathrm{n}$ & Age & $\mathrm{n}$ \\
\hline $1 \mathrm{a}$ & $<3$ & 2 & $<2.4$ & 29 \\
\hline $1 \mathrm{~b}$ & $<3$ & 16 & $<2.9$ & 64 \\
\hline $1 \mathrm{c}$ & $<3$ & 62 & 12.5 & 171 \\
\hline $2 \mathrm{a}$ & 15.6 & 334 & 15.1 & 142 \\
\hline $2 b$ & 27.9 & 114 & 22.6 & 95 \\
\hline $2 c$ & $>38.5$ & 269 & 31.3 & 109 \\
\hline $3 a$ & $>47.9$ & 27 & 38.3 & 44 \\
\hline $3 b$ & $>53.6$ & 26 & 40.5 & 43 \\
\hline $3 c$ & $>52.8$ & 24 & $>46.0$ & 116 \\
\hline $4 a$ & $>62.0$ & 4 & $>51.4$ & 64 \\
\hline $4 \mathrm{~b}$ & $>62.0$ & 7 & $>73.1$ & 19 \\
\hline $4 \mathrm{C}$ & - & - & $>84.4$ & 19 \\
\hline $4 d$ & - & - & $>89.7$ & 42 \\
\hline
\end{tabular}


The development of the 1978 autumn spawned larvae was dominated by a very lengthy Stage 2 which followed a rapid progression through the yolk sac Stage 1 (Fig. 4). No larvae in 1978 reached metamorphosis within the 61 to $62 \mathrm{~d}$ period of the experiment while about half of the final sample were only at Stage 2. The extremes of development at termination ranged from Stage $2 \mathrm{a}$ to pre-metamorphosis Stage $4 \mathrm{~b}$. In contrast the stage development times were much more uniform in spring 1980. No particular stage dominated and after $64 \mathrm{~d}$ (the duration of the 1978 experiment) about $10 \%$ of the larvae had already metamorphosed while the stages themselves ranged from $3 \mathrm{~b}$ to $4 \mathrm{c}$.

An estimate of the average stage duration was derived using the relation of Crisp (1954) where the proportion of time occupied by a given substage will be:

$$
\mathrm{t}_{\mathrm{n}} / \mathrm{T}=\sum_{\mathrm{i}}\left(\mathrm{S}_{\mathrm{n}} / \mathrm{S}\right)_{1} \triangle_{\mathrm{ti}} / \sum_{\mathrm{n}} \sum_{\mathrm{i}}\left(\mathrm{S}_{\mathrm{n}} / \mathrm{S}\right)_{1} \triangle_{\mathrm{ti}}
$$

where $t_{n}=$ time interval between substage $\mathrm{n}$ and $\mathrm{n}+1_{i}\left(\mathrm{~S}_{\mathrm{n}} / \mathrm{S}\right)_{1}=$ fraction of the total number of the ith sample lying between Stages $n$ and $n+1 ; \Delta t_{i}$ is half the time interval between the $(i-1)$ th and $(i+1)$ th sample. Since the total time of development $(T)$ was not known for the larvae in the bags, especially in the autumn 1978 experiment, $T$ was set at the duration time of the 1978 bags and on the nearest equivalent sampling date in spring 1980 . These values were 61 and $62 \mathrm{~d}$ for $\mathrm{C} 1-78$ and $\mathrm{C} 2-78$ respectively and $64 \mathrm{~d}$ after hatching for all the 1980 bags. Numbers within individual samples were also weighted to allow for unequal sample sizes (Doyle 1977). This gave a direct comparison of the rates of development during a defined period in autumn 1978 and spring 1980 (Fig. 5). The patterns were very different since about
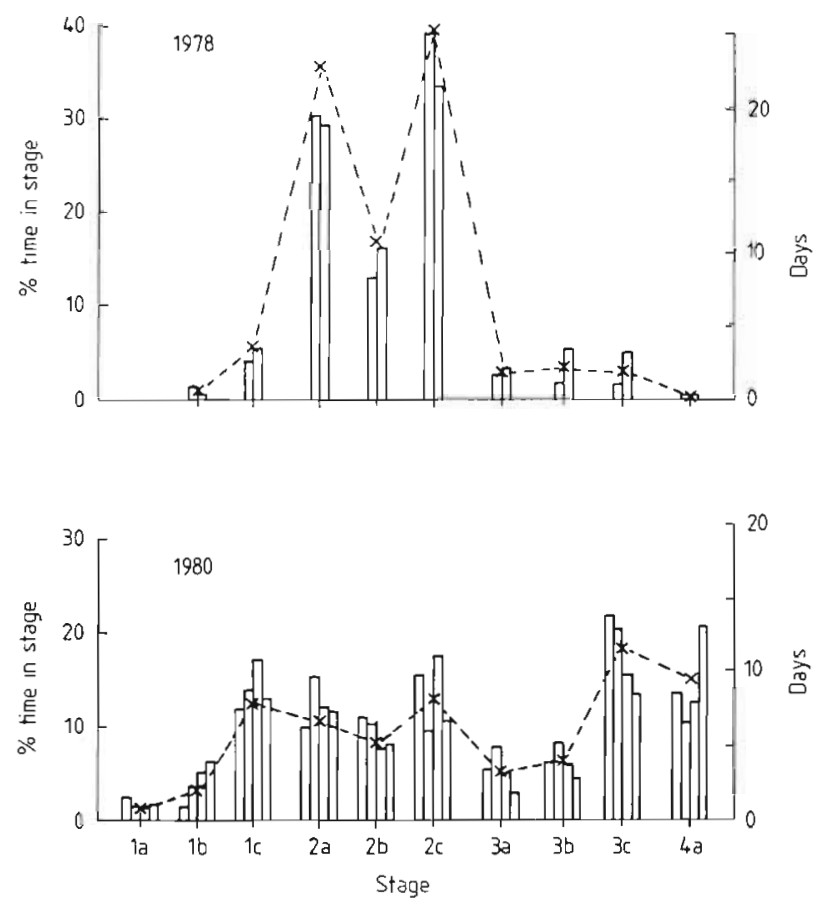

Fig. 5. Clupea harengus. Duration of developmental stages of herring larvae during rearing periods of 61 and $62 \mathrm{~d}$ in autumn 1978 and $64 \mathrm{~d}$ in spring 1980. Individual values from populations $\mathrm{C} 1$ - and $\mathrm{C} 2-78$ and $\mathrm{T} 1-, \mathrm{C} 1-, \mathrm{C} 2-, \mathrm{T} 2-80$ illustrated sequentially. Dashed line represents mean rate in days 'corrected' to constant $10^{\circ} \mathrm{C}\left(\mathrm{Q}_{10}=2.7\right.$, see p. 31)

$80 \%$ of this period of development in autumn was spent as Stage 2 larvae in contrast to $30 \%$ to $40 \%$ of time at the same stage in spring.

In autumn 1978 the larvae were lighter than the spring 1980 larvae at Stages 1 and 2 (Table 7). However, by the time Stage 3a had been reached the autumn and spring spawned larvae were similar in weight. The 1978 larvae were slightly lighter at

Table 7. Clupea harengus. Mean dry weight (mg) of developmental stages of herring larvae

\begin{tabular}{|ccccccr|}
\hline Stage & \multicolumn{2}{c}{1978 (Autumn) } & \multicolumn{3}{c}{1980 (Spring) } \\
& \multicolumn{1}{c}{ C1-78 } & C2-78 & T1-80 & T2-80 & C1-80 & C2-80 \\
\hline 1a & - & - & 0.13 & 0.10 & 0.13 & 0.11 \\
1b & 0.07 & 0.06 & 0.13 & 0.12 & 0.14 & 0.13 \\
1c & 0.07 & 0.06 & 0.12 & 0.11 & 0.12 & 0.10 \\
2a & 0.13 & 0.14 & 0.20 & 0.18 & 0.20 & 0.18 \\
2b & 0.21 & 0.24 & 0.36 & 0.40 & 0.33 & 0.30 \\
2c & 0.40 & 0.41 & 0.54 & 0.70 & 0.62 & 0.62 \\
3a & 0.83 & 1.00 & 0.84 & 1.39 & 1.03 & 1.00 \\
3b & 1.18 & 1.06 & 1.05 & 1.33 & 1.31 & 1.53 \\
3c & 1.68 & 2.20 & 1.57 & 2.77 & 2.47 & 3.07 \\
4a & 3.94 & 3.42 & 2.11 & 5.94 & 6.35 & 4.89 \\
4b & 6.31 & 7.83 & 2.74 & 13.94 & 8.10 & 10.72 \\
4c & - & - & 14.00 & 29.72 & 29.05 & 32.73 \\
4d & - & - & 49.91 & 113.29 & 138.06 & 152.05 \\
\hline
\end{tabular}


Stages $4 \mathrm{a}$ and $4 \mathrm{~b}$, but this was most probably due to the small sample size of the autumn larvae achieving that stage of maturity (Table 6). In spring 1980 it was also evident (Table 7 ) that the sizes at each stage of the larvae in T1-80 were much smaller from Stage 2c onwards than in the other enclosed populations of that year and smaller than the autumn 1978 larvae from Stage $3 a$ onwards. This latter contrast occurred in larval populations with similar growth rates (Table 4).

\section{Weight/length relations}

In most organisms, including fish (Ricker 1979), the weight on length relation is best described by a simple power law. However, a curvilinear relation was still evident in the logarithmic plots of the dry weight on length data for the herring larvae (Fig. 6). This was most evident in the spring 1980 larvae and was most probably due to the initial weight loss in hatching larvae through yolk consumption (Blaxter 1971, Vilela \& Zijlstra 1971).

The data sets were divided at a morphological stage based on the presence or absence of yolk sac. Since morphological definition was not very precise, the median standard length values for pre and post yolk sac stages were used for the maximum size of yolk sac and minimum size of post yolk sac larvae respectively. The transitional data between the stage medians was ignored.

Relations for the yolk sac larvae were mostly nonsignificant (not listed) while the dry weight of all the post yolk sac larvae was highly and positively correlated with length (Table 8). Comparisons between the regression lines showed that the slopes in the autumn 1978 relations were not significantly different while, in spring 1980, only C1- and C2-80 were similar. The slopes of closest similarity between the years, C2-78 and T1-80, were significantly different $(\mathrm{P}<0.001)$. Combined relations within each season most effectively contrast the different length-weight relations between years (Table $8 \mathrm{~b}$ ). In this case both slopes and intercepts were significantly different between seasons $(\mathrm{P}<0.001)$.

\section{Larval feeding and food populations}

\section{Feeding}

This is only a brief résumé since the subject will be dealt with in greater detail in a separate publication.

As expected (Blaxter \& Hunter 1982) the diet of the herring larvae broadened as the larvae aged and as they became increasingly able to capture larger organ- isms. In both autumn and spring copepod nauplii were the predominant item in the diets throughout and formed the bulk of the diet for the first-feeding larvae. Of the other organisms in the diet calanoid copepodites and lamellibranch veligers were most consis-
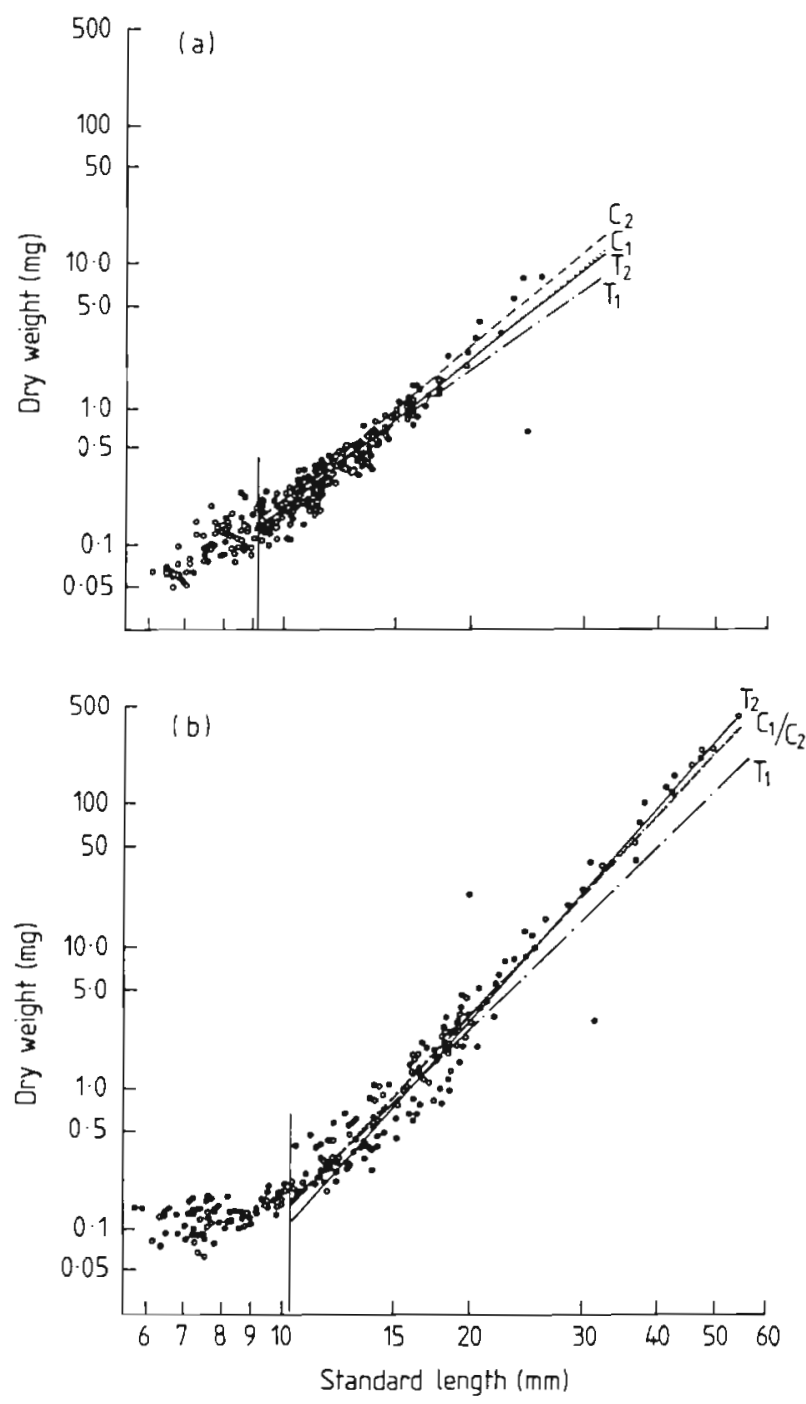

Fig. 6 Clupea harengus. Standard length/dry weight relations of (a) autumn 1978 and (b) spring 1980 herring larvae reared in bags. Entire data sets shown only for $\mathrm{C} 1-78$ and $\mathrm{C} 1$ 80 populations. Regression lines for all post yolk-sac larvae superimposed. Minimum size of post yolk-sac larvae indicated by vertical line

tently present in both seasons. Cyclopoid copepodites featured in both seasons but were perhaps more prevalent in the diets of the autumn larvae. However, though less abundant than the nauplii, the greater size of these other food items enhanced the significance of their contribution to the larval diet. 
Table 8. Clupea harengus. Length weight relations of post yolk sac herring larvae in enclosures. Regression parameters of dry weight $(\mathrm{mg})$ on standard length $(\mathrm{mm})$ power relation ( $\log _{10}$ transformed)

\begin{tabular}{|c|c|c|c|c|c|c|c|}
\hline & $\begin{array}{l}\text { Minimum } \\
\text { length }\end{array}$ & $\log _{10} a$ & $\mathrm{SE}$ & $b$ & SE & I & $\mathrm{n}$ \\
\hline T1-78 & 8.8 & -4.025 & 0.264 & 3.257 & 0.258 & 0.830 & 74 \\
\hline $\mathrm{T} 2-78$ & 9.4 & -4.470 & 0.158 & 3.690 & 0.147 & 0.930 & 100 \\
\hline C1-78 & 9.2 & -4.361 & 0.092 & 3.600 & 0.084 & 0.946 & 219 \\
\hline C2-78 & 9.6 & -4.562 & 0.098 & 3.800 & 0.088 & 0.949 & 205 \\
\hline $\mathrm{T} 1.80$ & 10.6 & -5.178 & 0.119 & 4.326 & 0.101 & 0.947 & 213 \\
\hline $\mathrm{T} 2-80$ & 10.4 & -6.139 & 0.130 & 5.107 & 0.104 & 0.977 & 118 \\
\hline C1-80 & 10.4 & -5.636 & 0.110 & 4.716 & 0.089 & 0.972 & 165 \\
\hline $\mathrm{C} 2-80$ & 10.2 & -5.680 & 0.083 & 4.760 & 0.064 & 0.990 & 118 \\
\hline \multicolumn{8}{|c|}{ Combined data; post yolk sac } \\
\hline 1978 & & -4.475 & 0.057 & 3.708 & 0.053 & 0.944 & 598 \\
\hline 1980 & & -5.687 & 0.052 & 4.756 & 0.042 & 0.976 & 614 \\
\hline
\end{tabular}
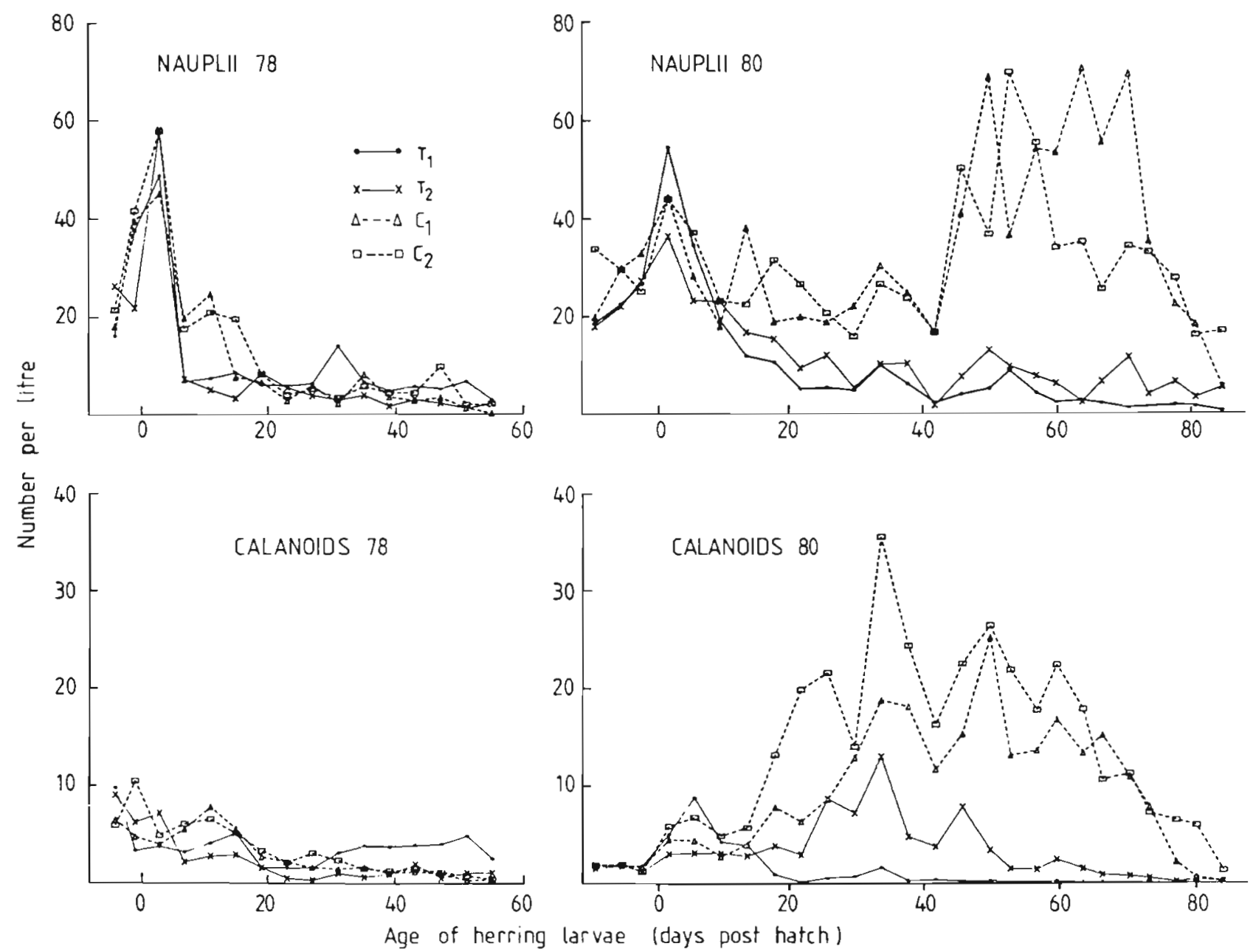

Fig. 7. Abundance of copepod nauplii and calanoid copepodites in autumn 1978 and spring 1980 bag experiments, related to age of herring larvae, where Day 0 was 15 September 1978 and 20 April 1980 


\section{Zooplankton}

The marked feature of the bag zooplankton populations, which are illustrated (Fig. 7 \& 8 ) in accordance with the dietary preferences of the herring larvae, was their steady decline in all 4 autumn bags and to a certain extent in the 2 treated (T1-80, T2-80) spring bags. In contrast the copepod naupliar and calanoid copepodite populations in the spring control systems (C1-80, C2-80) peaked in the latter half of the experimental period but they too eventually fell to a low level. Despite these differences which emerged as the experiment progressed, the zooplankton population levels during the first few days after hatching were roughly equivalent. In biomass terms the standing stocks were between 100 and $160 \mathrm{mg}$ dry wt $\mathrm{m}^{-3} \mathrm{du}-$ ring the week after hatching in autumn 1978 and between 100 and $180 \mathrm{mg}$ dry wt $\mathrm{m}^{-3}$ for the equivalent period in spring 1980. Initial concentrations of the copepod nauplii were also similar ranging between 20 and 60 nauplii $1^{-1}$ in all systems in both seasons.

The populations of nauplii in particular and of copepodites declined markedly after the addition of the 'produced water' (Fig. 7). Implications of the toxic effects of 'produced water' are discussed elsewhere but one of the consequences was that the zooplankton population levels in the treated bags in spring 1980 (T1, T2) were very similar to those of the controls ( $\mathrm{C} 1$, C2) in autumn 1978. This was particularly so in T1-80.

\section{DISCUSSION}

Are the differing patterns of development of autumn and spring spawned herring reared in similar large enclosures the result of differing growth strategies (Sinclair \& Tremblay 1984)? Growth rates varied widely and were slowest in autumn, (Fig. $2 \& 3$ ) and
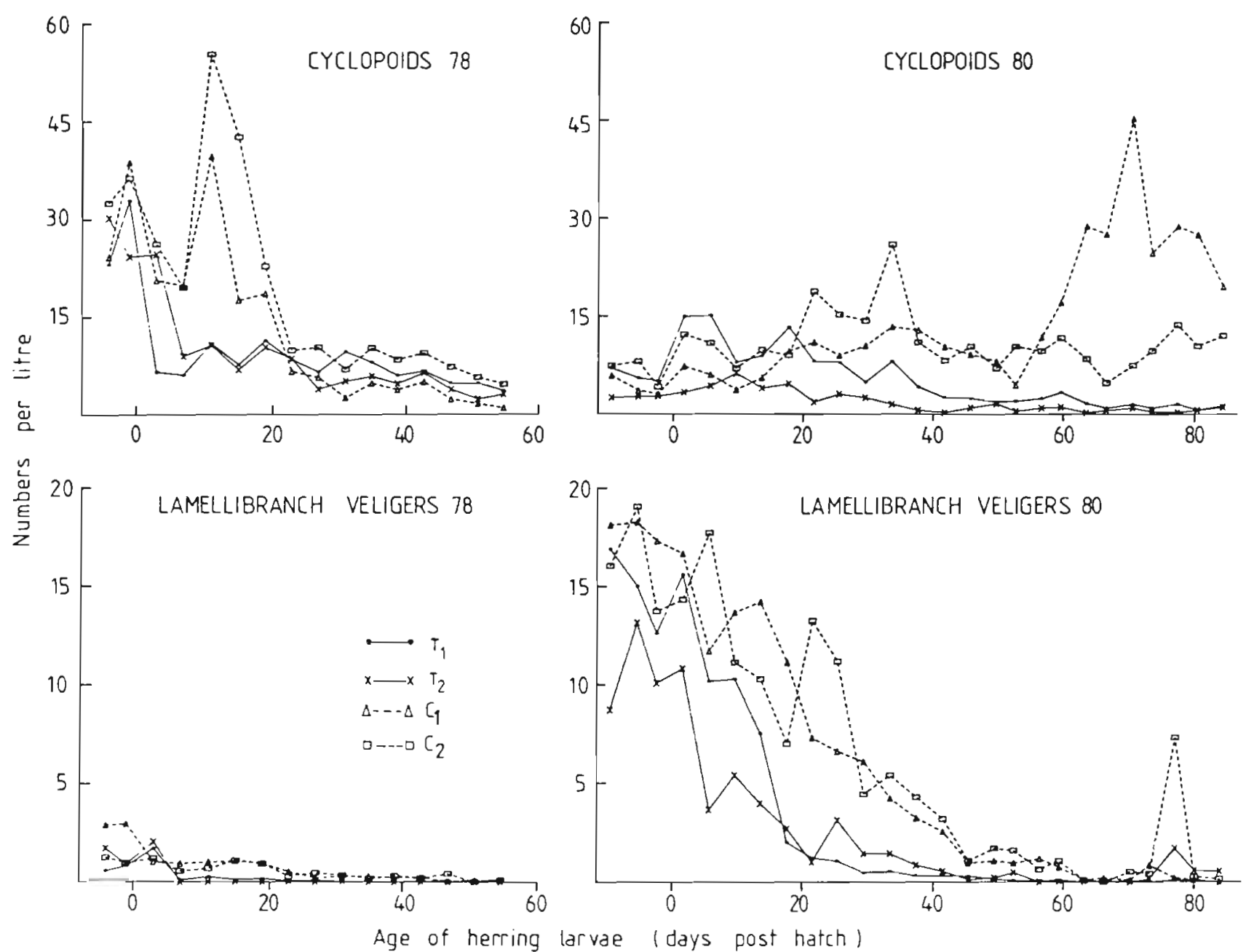

Fig. 8. Abundance of cyclopoid copepodites and lamellibranch veligers in autumn 1978 and spring 1980 bag experiments, related to age of herring larvae, where Day 0 was 15 Sep 1978 and 20 Apr 1980 
there was also a significant difference between the length/weight relations (Fig. 6, Table 8). Most importantly the developmental patterns of the larvae from the 2 seasons were different (Fig. $4 \& 5$, Table $6 \& 7$ ), the autumn larvae being characterised by a prolonged immediate post yolk sac period. However, it is necessary to determine whether these differences were caused by extrinsic factors or whether they reflect intrinsic features of the larvae themselves.

Developmental rates, such as the time to larval metamorphosis, are a function of size and age (Ryland 1966, Policansky 1983), and are thus directly proportional to growth rate. Many observations have shown that larval growth is directly related to feeding rate (Hunter 1981) and that feeding rate itself is a function of food concentration (Houde \& Schekter 1980). Herring larvae, like most fish larvae, are visual feeders and their diurnal feeding period will be limited by available light (Ivlev 1961, Blaxter 1966, Blaxter \& Staines 1971). Larval growth rates will also be influenced by temperature (Blaxter \& Hunter 1982).

In terms of larval development equivalent temperature and day length values changed inversely as each season progressed (Fig. 9). Temperatures were considerably greater at hatching in the autumn $\left(12^{\circ} \mathrm{C}\right)$ than in the spring $\left(7.8^{\circ} \mathrm{C}\right)$ but converged during the first ca $50 \mathrm{~d}$ of development. Hence for a $Q_{10}$ of 2.7 (a compromise value derived for incubation period from our observations and those of Blaxter 1956) the

\begin{tabular}{|c|c|c|}
\hline September & October & November \\
\hline April & yy & June \\
\hline
\end{tabular}
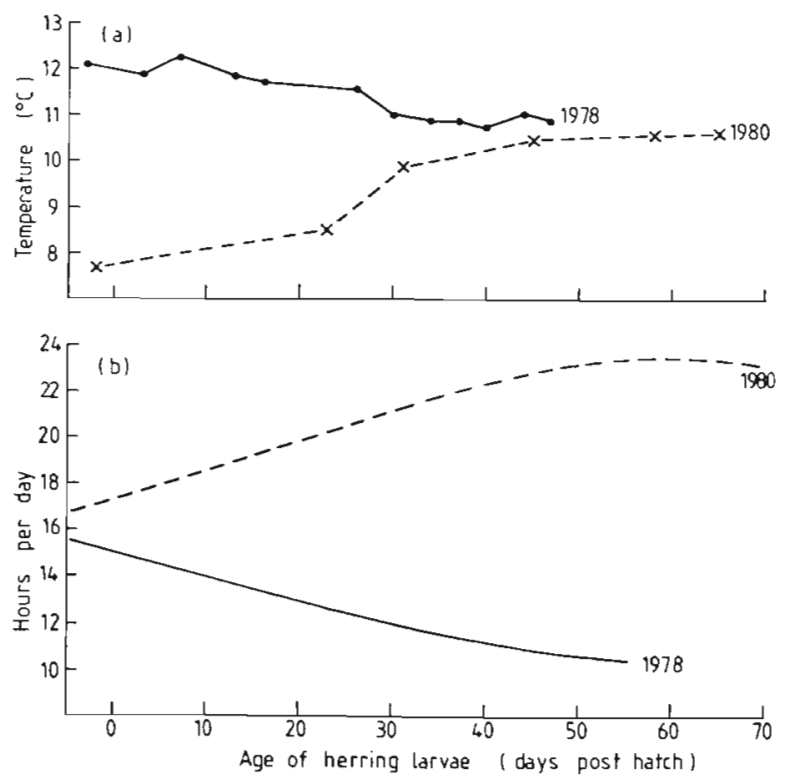

Fig. 9. (a) Water temperature, $5 \mathrm{~m}$ in bag T1-78 and T1-80, and (b) duration of surface light levels above 0.1 lux (Blaxter \& Staines 1971) during the larval rearing periods in autumn 1978 (solid line) and spring 1980 (dashed line) developmental rate of the autumnal larvae would be 149,115 and $103 \%$ of the spring larvae at 10,30 and $50 \mathrm{~d}$ post hatch respectively. However, if the estimates of stage duration times for each season are corrected to a uniform $10^{\circ} \mathrm{C}$ the broad pattern differences still remain (Fig. 5).

In contrast, photoperiods, in terms of the minimum light necessary for feeding at the surface (0.1 lux, Blaxter \& Staines 1971) at the latitude of Loch Ewe, were closer at hatching, $15 \mathrm{~h}$ in the autumn and $17.5 \mathrm{~h}$ in the spring, but diverged as development progressed (Fig. 9b). Using Blaxter's (1966) estimates of the volume searched per day, the autumnal larval feeding capacity reduced from $80 \%$ of the spring larvae at $10 \mathrm{~d}$ old, to $61 \%$ at $30 \mathrm{~d}$ and to $47 \%$ at age $50 \mathrm{~d}$. Both Ivlev (1961) for herring and Laurence (1977) for winter flounder have estimated the length of photoperiod necessary to sustain larval growth at known food densities. However, both assumed that the larvae fed continuously during the day although field data on gut fullness of herring larvae suggests a diel periodicity with a maximum content at dusk (Blaxter 1965, Bainbridge \& Forsyth 1971). A more complex, i.e. optimal, photoperiodic relation has been described for subtropical larval sea bream (Dowd \& Houde 1980) where growth and survival were best at the ambient photoperiod of $13 \mathrm{~h}$. A longer photoperiod of $19 \mathrm{~h}$ resulted in better growth only at the lowest food concentration tested.

Food abundance is the other principal extrinsic factor affecting rate of larval growth. It is also the least predictable (particularly at the onset of larval feeding) although zooplankton population numbers characteristically decline as winter approaches. In these experiments zooplankton populations in the spring bags (1980) were artificially increased to a copepod naupliar stocking level equivalent to that of the 1978 autumn experiment (Fig. 7), since in normal circumstances, the spring naupliar levels at Loch Ewe would be 5 to $10 \times$ lower than in autumn. As the experiments progressed the zooplankton populations declined in the autumn while, in spring, in the control enclosures, the calanoids bloomed. These differences were reflected in the growth rates of the herring larval populations (Table $3 \& 4$ ).

In spring 1980 it was also apparent that the larval growth rate was inversely proportional to the larval population density; the largest bag population during the first part of the experiment, T1-80 (Fig. 1), having the slowest growth rate for that year. Fortuitously the growth rate of this population (daily instantaneous growth rage [g] of 0.045 ) was very similar to the rates measured for the 2 pollutant-free control populations in autumn 1978, 0.04 and 0.044 for $\mathrm{C} 1$ - and $\mathrm{C} 2-78$ respectively. Comparisons of the stage/weight relations of these populations (Table 7) indicates that, in 
spite of the similarity between growth rates, the developmental patterns were different. This of course is emphasized in the stage duration profiles (Fig. 5) where the T1-80 population closely resembles the other spring larval populations. This differentiation between seasons was also emphasized by the differences in length/weight relations (Table 8).

The most important seasonal difference, however, was in egg size and subsequent yolk-sac larval size. The hatching larval weight ratio for spring : autumn was about $2: 1$ and, if cohorts of larvae from each season grew at the same rate, this difference would obviously be maintained. For instance at a daily instantaneous growth rate $(\mathrm{g})$ of 0.04 the weight after $60 \mathrm{~d}$ in the spring larvae would have been $1.52 \mathrm{mg}$ compared to 0.74 for the autumnal larvae. At the fastest autumnal rate measured, 0.084 (Table 5), the eventual weight for autumnal larvae after $60 \mathrm{~d}$ would have been $10.3 \mathrm{mg}$ which was still below the average weight for the final larval stage $(4 \mathrm{c})$ in the slowest growing ( $\mathrm{T} 1$ 80) spring larvae and comparable to the weights at Stage $4 \mathrm{~b}$ for spring larvae growing at nearly the same rate (Table 7 ). Thus within the range of measured growth rates the Minch autumnal larvae could not achieve metamorphosis by mid-November.

The observations made in these 2 series of bag experiments do not refute any of the hypotheses relating egg size differences to ecological advantage in terms of larval survival at low food levels (Blaxter \& Hempel 1963) or predation and fecundity (Ware 1975). Indeed these considerations must still apply. However, our observations do offer an additional interpretation of the differences in egg size based on differing growth strategies for larvae from different stocks spawning at different times of the year (Sinclair \& Tremblay 1984). The spring-spawned herring larva grows rapidly and achieves metamorphosis quickly while the autumn larva remains as a larva for a prolonged period. Clearly low winter temperature, shorter light periods and reduced food levels will themselves result in slow growth and development, but in favourable initial autumnal conditions of high temperature and high food abundance, early growth would be rapid and prewinter metamorphosis might occur. Autumn spawners producing small eggs may therefore have a selective advantage, since early development is prolonged and pre-winter metamorphosis is thus precluded. The effect of smaller size is seen in the relative times spent in the immediate post yolk sac stage of development. Prior to the onset of this second stage the weight differences between autumn and spring larvae were much the same as at hatching, with average dry weights at Stage $1 \mathrm{~d}$ of $0.065 \mathrm{mg}$ in the autumn compared with $0.11 \mathrm{mg}$ in the spring. After Stage 2, however, the weight differential between the larvae from each season had narrowed considerably, since average dry weights for Stage 3 had increased to $0.92 \mathrm{mg}$ and $1.07 \mathrm{mg}$ for autumn and spring larvae respectively (Table 7).

This suggestion that there is selection for a check in development in autumn larvae begs the intriguing question of role reversal. What would happen to large spring-hatching larvae in the autumn and vice versa? Baltic and Elbe herring stocks indicate that larvae from small eggs, if produced early enough in the summer in appropriate environmental conditions (Hempel \& Blaxter 1967), can achieve metamorphosis before the onset of winter. Unfortunately there are no Baltic herring stocks producing large eggs and also, as yet, it is not possible to cryopreserve herring eggs. The use of frozen sperm in a spring-sperm : autumn-egg cross fertilization produced only small autumn-sized hatching larvae (Blaxter 1956). It would, however, be possible to investigate the interaction of day length, temperature regime and food abundance on larval growth and development in a simulation of seasonal conditions. Such experiments should help to resolve the question whether the prolonged development of the autumn spawning herring larva is genetically determined or whether it depends on the interaction between small initial size and extrinsic factors.

If it stands, this hypothesis on herring egg size differences lends support to the suggestion by Sinclair \& Tremblay (1984) that the size at a particular spawning time is determined by the need for herring larvae to metamorphose within a more limited period of the year.

Acknowledgements. We would like to acknowledge those members of the Marine Laboratory, Aberdeen staff who participated in the Loch Ewe enclosure experiments. In particular we thank N. T Nicoll who analysed larval gut contents S. J. Hay and A. Smith for their zooplankton analysis, and J. Dunn for organising the extensive hardware. Our thanks are also due to R. Jones and A. D. Hawkins for their critical comments on the manuscript.

\section{LITERATURE CITED}

Bagenal, T. B. (1966). The ecological and geographical aspects of the fecundity of plaice J. mar. biol. Ass. U.K. 46 : $161-186$

Bagenal, T B. (1971). The inter-relation of the size of fish eggs, the date of spawning and the production cycle. J. Fish Biol. 3: 207-219

Bainbridge, V., Forsyth, D. C. T (1971). The feeding of herring larvae in the Clyde. Rapp. P.-v. Réun. Cons. int. Explor. Mer 160: 104-113

Blaxter, J. H. S. (1956). Herring rearing - II. The effect of temperature and other factors on development. Mar Res. Scot. No. 5, p. 1-19

Blaxter, J. H. S. (1965). The feeding of herring larvae and their 
ecology in relation to feeding. Calif. coop. ocean. Fish. Invest. Rep. 10: 79-88

Blaxter, J. H. S. (1966). The effect of light intensity on the feeding ecology of herring. In: Bainbridge, R., Evans, G. C., Rackham, O. (ed.) Light as an ecological factor Blackwell, Oxford, p. 393-409

Blaxter, J. H. S. (1971). Feeding and condition of Clyde herring larvae. Rapp. P.-v. Réun. Cons. int. Explor. Mer. 160: $128-136$

Blaxter, J. H. S. (1975). Reared and wild fish - how do they compare? In: Persoone, G., Jaspers, E. (ed.) 10th European symposium on marine biology Vol. 1. Universal Press, Wettern, Belgium, p. 11-26

Blaxter, J. H. S., Hempel, G. (1963). The influence of egg size on herring larvae (Clupea harengus L.). J. Cons. perm. int. Explor. Mer. 28: 211-240

Blaxter, J. H. S., Hunter, J. R. (1982). The biology of clupeoid fishes. Adv. mar. Biol. 20: 1-223

Blaxter, J. H. S., Staines, M. E. (1971). Food searching potential in marine fish larvae. In: Crisp, D. J. (ed.) 4th European marine biology symposium. Cambridge Univ. Press, Cambridge, p. 467-485

Burd, A. C., Howlett, G. J. (1974). Fecundity studies on North Sea herring. J. Cons. int. Explor. Mer. 35: 107-120

Crisp, D. J. (1954). The breeding of Balanus porcatus (de Costa) in the Irish Sea. J. mar. biol. Ass. U.K. 33: 473-496

Cushing, D. H. (1967). The grouping of herring populations. J. mar. biol. Ass. U.K 47: 193-208

Cushing, D. H. (1969). The regularity of spawning of some fishes. J. Cons. int. Explor. Mer. 33: 81-92

Cushing, D. H. (1973). The natural regulation of fish population. In: Harden-Jones, F. R. (ed.) Sea fisheries research. Paul Elek Ltd, London, p. 339-412

Cushing, D. H. (1975). Marine ecology and fisheries. Cambridge Univ. Press, London

Davies, J. M., Baird, I. E., Massie, L. C., Hay, S. J., Ward, A. P. (1980). Some effects of oil-derived hydrocarbons on a pelagic food web from observations in an enclosed ecosystem and a consideration of their implications for monitoring. Rapp. P.-v. Réun. Cons. int. Explor. Mer. 179: 201-211

De Silva, S. S. (1973). Abundance, structure, growth and origin of inshore clupeoid populations of the west coast of Scotland. J. exp. mar. Biol. Ecol. 12: 119-144

Dowd, C. E., Houde, E. D. (1980). Combined effects of prey concentration and photoperiod on survival and growth of larval sea bream, Archosargus rhomboidalis (Sparidae). Mar. Ecol. Prog. Ser. 3: 181-185

Doyle, M. J. (1977). A morphological staging system for the larval development of the herring, Clupea harengus L. J. mar. biol. Ass. U.K. 57: 859-867

Gamble, J. C., MacLachlan, P., Nicoll, N. T., Baxter, I. G. (1981). Growth and feeding in Atlantic herring larvae reared in large plastic enclosures. Rapp. P.-v. Réun. Cons. int. Explor. Mer. 178: 121-134

Gatten, R. R., Sargent, J. R., Gamble, J. C. (1983). Diet induced changes in fatty acid composition of herring larvae reared in enclosed ecosystems. J. mar. biol. Ass. U.K. 63: $575-584$

Hempel, G. (1965). Fecundity and egg size in relation to the environment. Spec. Publs int. Commn NW. Atlant. Fish., No. 6: $687-690$
Hempel, G., Blaxter, J. H. S. (1963). Egg weight in Atlantic herring (Clupea harengus L.). J. Cons. perm. int. Explor Mer 31: $170-195$

Houde, E. D. (1978). Critical food concentrations for larvae of three species of subtropical marine fishes. Bull. mar. Sci. 28: $395-411$

Houde, E. D., Schekter, R. C. (1980). Feeding by marine fish larvae: developmental and functional responses. Environ. Biol. Fish. 5: 315-334

Hunter, J. R. (1981). Feeding ecology and predation of marine fish larvae. In: Lasker, R. (ed.) Marine fish larvae, morphology, ecology and relation to fisheries. Washington Sea Grant Program. Univ. of Washington Press, Seattle, p. $33-77$

Iles, T. D. (1964). The duration of maturation stages in herring. J. Cons. perm. int. Explor. Mer. 29: 166-188

Iles, T. D., Sinclair, M. (1982). Atlantic herring: stock discreteness and abundance. Science 215: 627-633

Ivlev, V. S. (1961). On the utilization of food by planktoneating fishes. Tr. Sevastop. Biol. Stn. Im. A. D. Kovalenskogo Akad. Nauk SSSR. 14: 188-201. (Fish. Res. Bd Can. Transl. Ser. 447, p. 1-17)

Laurence, G. C. (1977). A bioenergenic model for the analysis of feeding and survival potential of winter flounder, Pseudopleuronectes americanus, larvae during the period from hatching to metamorphosis. Fish. Bull. U.S. 75: 529-546

Mann, R. H. K., Mills, C. A. (1979). Demographic aspects of fish fecundity. In: Miller, P. J. (ed.) Fish phenology. Symp. Zoo. Soc. Lond. No. 44. Academic Press, London, p. $161-177$

Marshall, S. M., Nicolls, P. M., Orr, A. P. (1937). On the growth and feeding of the larval and post larval stages of the Clyde herring. J. mar. biol. Ass. U.K. 22: 245-267

Øiestad, V. (1982). Application of enclosures to studies on the early life history of fishes. In: Grice, G. D., Reeve, M. R. (ed.) Marine mesocosms. Biological and chemical research in experimental systems. Springer-Verlag, New p. $49-62$

Policansky, D. (1983). Size, age and demography of metamorphosis and sexual maturation in fishes. Am. Zool. 23: $57-63$

Ricker, W. E. (1979). Growth rates and models. In: Hoar, W. S., Randall, D. J., Brett, J. R. (ed.) Fish physiology, Vol. VIII, Bioenergenics and growth. Academic Press, New York, p. 678-743

Ryland, J. S. (1966). Observations on the development of larvae of the plaice, Pleuronectes platessa L., in aquaria. J. Cons. perm. int. Explor. Mer. 30: 177-195

Sinclair, M., Tremblay, M. J. (1984). Timing of spawning of Atlantic herring (Clupea harengus harengus). Can. J. Fish. Aquat. Sci. 41: 1055-1065

Steele, J. M., Farmer, D. M., Henderson, E. W. (1977). Circulation and temperature structure in large marine enclosures. J. Fish. Res. Bd Can. 34: 1095-1104

Vilela, M. H., Zijlstra, J. J. (1971). On the condition of herring larvae in the central and southern North Sea. Rapp. P.-v. Réun. Cons. int. Explor. Mer. 160: 137-141

Ware, D. M. (1975). Relation between egg size, growth and natural mortality of larval fish. J. Fish. Res. Bd Can. 32: 2503-2512 